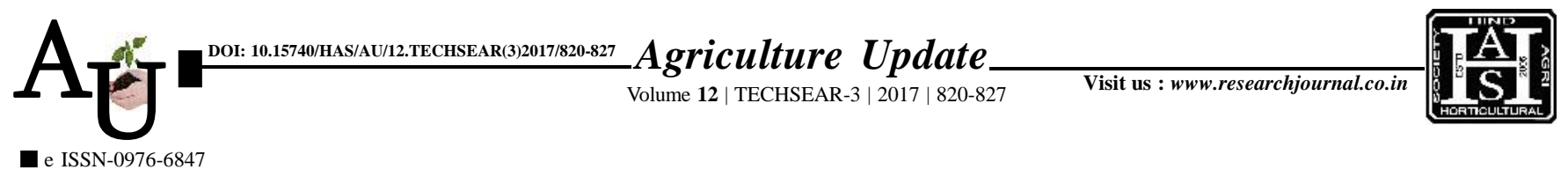

\title{
Research Article: Fixation and release pattern of potassium under graded levels of potassium application in soils of Kurnool district
}

\section{RAJEEVANA, P. KAVITHA, M.SREENIVASA CHARI AND M. SRINIVASA REDDY}

Article Chronicle: Received :

13.07.2017;

Accepted :

28.07.2017

KeY Words :

Soil, Potassium, DAI, Water soluble

Author for correspondence :

I. RAJEEVANA

Department of Soil

Science and Agricultural

Chemistry, Agriculture

College (ANGRAU),

Mahanandi, GUNTUR

(A.P.) INDIA

Email : kavitha.ssac@

gmail.com

See end of the article for

authors' affiliations
SUMMARY : An incubation was carried out in ten surface soil samples $(0-15 \mathrm{~cm})$ to study the fixation and release pattern of $\mathrm{K}$ under the influence of different levels of potassium in soils of Kurnool district. The soils under study were moderately coarse to fine in texture, neutral to slightly alkaline, non saline and non-calcareous. Water soluble potassium content increased from 0 to 14 DAI and later on gradually decreased from 21 DAI to 120 DAI in fertilizer treatments. However, in control water soluble K content gradually decreased from 0 to 120 DAI but still existence of water soluble form upto 120 DAI. Available $\mathrm{K}$ content increased in control from 0 to $14 \mathrm{DAI}$ whereas in fertilized plots (from 30 to $90 \mathrm{~kg} \mathrm{~K}_{2} \mathrm{O} \mathrm{ha}^{-1}$ ) increased upto 21 DAI, later on gradually decreased upto 120 DAI. Unlike water soluble and available potassium mean fixed potassium gradually increased upto 0 to $120 \mathrm{DAI}$ in fertilizer treatments, whereas in control mean fixed form of $\mathrm{K}$ decreased gradually from 0 to $120 \mathrm{DAI}$.

How to cite this article : Rajeevana, I., Kavitha, P., Chari, M.Sreenivasa and Reddy, M. Srinivasa (2017). Fixation and release pattern of potassium under graded levels of potassium application in soils of Kurnool district. Agric. Update, 12(TECHSEAR-3) : 820-827; DOI: 10.15740/HAS/AU/12.TECHSEAR(3)2017/820827. 